\author{
Asian Journal of \\ Medical and Biological Research \\ ISSN 2411-4472 (Print) 2412-5571 (Online) \\ www.ebupress.com/journal/ajmbr
}

\title{
Article \\ Study on anatomy and postnatal development of sublingual salivary glands in Black Bengal goat
}

\author{
Shah Md. Abdur Rauf* \\ Department of Veterinary and Animal Sciences, University of Rajshahi, Rajshahi-6205, Bangladesh \\ *Corresponding author: Professor Dr. Shah Md. Abdur Rauf, Department of Veterinary and Animal Sciences, \\ University of Rajshahi, Rajshahi-6205, Bangladesh. E-mail: rauf_94@yahoo.com
}

Received: 02 June 2020/Accepted: 26 June 2020/ Published: 30 June 2020

\begin{abstract}
There are three pairs of salivary glands in Black Bengal goat namely parotid, mandibular and sublingual salivary gland. Information regarding the sublingual salivary gland is very limited and confined in adult goat only, no reports available concerning the postnatal development of the goat sublingual gland to date. Present study is carried out to fill up the gap of information regarding this gland. In day old kid the sublingual gland is measured $2.5 \pm 0.30 \mathrm{~cm}$ in length, $0.25 \pm 0.08 \mathrm{~cm}$ in breadth, $0.15 \pm 0.01 \mathrm{~cm}$ in thickness and 0.09 $\pm 0.01 \mathrm{~g}$ in weight which became little more than double in each parameter in adult. The main sublingual duct is formed by the union of 5-7 radicles from monostomatic part of the gland and opened at sublingual caruncle. 2630 small tortuous ducts arise from the polystomatic part and opened independently in a row of microscopic orifices of the sublingual fold. Gradual histological development shows the glandular units composed of tubulealveolar acini which are mostly mucous in type. The mucous acini composed of pyramidal shape cells resting on a basement membrane. In day old kid, the acini have distinct lumen. The cells contain rounded nuclei at their basal part and lack of zymogenic granules indicating less functional state of the glands. Along the advancement of age the size of lobes and lobules are increased, the lumens of the mucous acini reduced in size, nuclei of the cells became flattened the zymogenic granules increased gradually. Mixed acini are more than the serous acini where a serous demilune is attached on a mucous acinus. The serous acini were less in number.
\end{abstract}

Keyword: sublingual gland; mucous acini; serous acini; intercalated duct

\section{Introduction}

Salivary gland is an important organ of mammals which secretes clear, tasteless fluid called saliva. The secretory cells making up the acini of these glandular tissues produce serous, mucous or mixed saliva. Saliva is secreted into the oral cavity via a series of ducts in the ductal system, and plays diverse roles by having digestive, antibacterial, buffering, lubricant, and water-balance functions (Genkins, 1978). Saliva is essential for microbial digestion in the rumen i.e. microbial fermentation (Pospieszng et al., 2010). Food chewed is mixed with salivary secretion thus saliva facilitates swallowing. Saliva may have evaporative cooling functions, depending on the species (Accili et al., 1994). Dysfunction of salivary secretion (hyposalivation) causes xerostomia (dry mouth) and sequentially leads to severe dental caries as well as oral mucosal disorders (Featherstone, 2000; Vissink et al., 2010). Hyposalivation is caused by systemic diseases such as Sjögren's syndrome and by pharmaceutical side effects, salivary stones, and tumors as well as medical treatments including radiotherapy (Burlage et al., 2001; Fox, 1998; Ship, 2004). The study of the salivary gland forms an important link between the anatomy and surgery. The salivary glands and ducts may be affected by inflammation, calculus formation, rupture or neoplasia. Sialoadenitis is commonly associated with salivary mucoceles. The recognition and treatment of these lesions depend on an adequate knowledge of anatomy (Stephen et al., 2010; Reece, 2004). Most mammals have at least three pairs of salivary glands. The parotid glands which lie just under the ear and behind the vertical rams of the mandible. The mandibular glands which are located in the intermandibular space and the sublingual gland at the base of tongue. Each of these glands 
drains into a main duct that has a single opening into the mouth. There are three pairs of salivary glands in Black Bengal goat (the native breed of goat which is famous for quality meat, hides and high prolificacy) namely parotid, mandibular and sublingual salivary gland (Islam, 1981; Rauf et al., 2004). Information regarding the sublingual salivary gland is very limited and confined in adult goat only. Although considerable attention has been directed towards the development of the gland in carnivores and rodents, there have been no reports concerning the postnatal development of the goat sublingual gland to date. The cat submandibular gland is incompletely differentiated at birth (Takagi, 1925) where as in the mouse, rat and hamster acini are not present at birth and glandular development is not completed until the animals attain maturity (Jacoby, 1959; Jacoby and Leeson, 1959; Dvorak, 1969; Yamashina and Barka, 1972; Devi and Jacoby, 1966).

Present study is carried out to investigate the anatomy, histology and postnatal development of sublingual salivary gland of Black Bengal goat for academic interest and to fill up the gap of information regarding the gland.

\section{Materials and Methods}

The study was conducted at the Department of Veterinary and Animal Sciences, University of Rajshahi. Fifteen Black Bengal goats of different ages and sexes were used for the gross and microscopic study. Goats consisted of three age groups such as kids of day old $(n=5), 6$ months old $(n=5)$ and 2 years old $(n=5)$. The goats were killed under anesthesia using $2 \%$ lignocaine hydrochloride and $0.9 \%$ saline was injected through the common carotid artery to flash the blood vessels. Then the goats were preserved by injecting the fixing solution containing $10 \%$ formalin, $1 \%$ phenol and $0.05 \%$ glycerin in distilled water. After 24 hours of preservation latex were injected through common carotid artery, then dissections were carried out. Muscles were removed from the cranial part of the mandible by reflecting the skin. Finally, the mandibles were broken gently with bone cutter to expose the sublingual salivary glands. The topography, shape, color, morphometry and weights were recorded. Measuring scale and electric balance were used to measure the length and weight of the glands, respectively. Dissecting microscope and magnifying glass were used to study the finer branches of blood vessels and duct system. For microscopic studies fresh glandular tissue from 15 goats were collected. The tissue samples were processed following standard procedure for histologic studies (Golbar et al., 2013). In brief, the tissues were dehydrated through ascending grades of alcohol, cleared by three changes in xylene then embedded in paraffin. The paraffin embedded tissues were sectioned at $5 \mu \mathrm{m}$ in thickness by using a semi-automatic rotary microtome (Mosbi ${ }^{\mathrm{TM}}$, China), routinely stained with Mayer's hematoxylin and Eosin (H\&E) and examined under a light microscope. The images of the tissue sections were grabbed by using a photographic microscope system.

\section{Results}

Sublingual salivary gland is the smallest among three pairs of salivary glands of goat. It is situated beneath the mucous membrane of the mouth between the lower part of the tongue and the mylohyoid muscle. The gland extends from a little behind the symphysis mandibulae upto the second or third lower cheek tooth. It is elongated flattened with nearly rounded ends. The caudal part of the gland is wider and become narrower gradually toward the cranial end. The gland has two surfaces and two borders. The lateral surface is flat and related to the mylohyoid muscle and the sublingual nerve. The medial surface is also flat and related to the genioglossus and styloglossus muscles and the mandibular duct. The dorsal border is slightly convex and related to the reflection of the mucous membrane from tongue to the jaw. The ventral border is also slightly convex and related to the mylohyoid muscle. The sublingual salivary gland is finely lobulated and covered with a thin capsule. The gland is cream colored in fresh condition and somewhat darker in preserved state. In day old kid the sublingual gland measured $2.5 \pm 0.30 \mathrm{~cm}$ in length, $0.25 \pm 0.08 \mathrm{~cm}$ in breadth, $0.15 \pm 0.01 \mathrm{~cm}$ in thickness and $0.090 \pm 5 \mathrm{~g}$ in weight. In young goat of 6 months age the sublingual gland measured $3.8 \pm 1 \mathrm{~cm}$ in length, $0.5 \pm 0.25 \mathrm{~cm}$ in breadth, $0.2 \pm 0.90 \mathrm{~cm}$ in thickness and $0.42 \pm 0.02 \mathrm{~g}$ in weight. In adult Black Bengal goat, the gland measured $5.2 \pm 0.60 \mathrm{~cm}$ in length, $0.8 \pm 0.30 \mathrm{~cm}$ in breadth, $0.36 \pm 0.10 \mathrm{~cm}$ in thickness, $0.8 \pm 0.10 \mathrm{~g}$ in weight. The gland is incompletely divided into two parts namely superior or polystomatic part and inferior or monostomatic part. The main sublingual duct is formed by the union of 5-7 radicles from monostomatic part of the sublingual gland in adult Black Bengal goat and passed cranially along the mandibular duct. The two ducts (mandibular and sublingual) pass cranio-dorsally over the lingual surface of the body of the mandible and leave the gland on the cranial end. The two ducts open at a common orifice at the sublingual caruncle in the floor of the mouth, cranio-lateral to the frenum of the tongue. 26-30 small tortuous ducts arose from the dorsal border of 
the polystomatic part of the sublingual gland pass dorsally and open independently in a row of microscopic orifices of the sublingual fold.

The sublingual gland is supplied by the sublingual artery, a branch of the lingual artery, at the medial aspects of hypoglossal muscle, and passes cranially towards the symphysis of the mandible. Shortly after its origin from the lingual artery the sublingual artery gives off 3-5 small branches to supply the sublingual gland (Figure 1).

The gland is drained by finer twigs of sublingual vein, which then passes along the ventral border of the gland and merge with the lingual vein.

The sublingual salivary gland of Black Bengal goat is enclosed with a thin connective tissue capsule. The gland is subdivided into lobes and lobules by loose connective tissue septa which also contain blood vessels, nerves etc. In day old kid the lobes are smaller in size and the lobules are indistinct. Interlober septum contains large number of collagen bundle. The glandular units composed of tubuloalveolar acini which are mostly mucous in type, some mixed acini (where serous demilunes capped at the outer part of the mucous acinus) are also found. The mucous acini composed of pyramidal cells with rounded nuclei resting on a basement membrane. The acini have distinct lumen. The cells contain rounded nuclei at their basal part and lack of zymogenic granules indicating less functional state of the glands (Figure 2). The mucous part of the mixed acini also have rounded nuclei. The serous acini are lined by pyramidal cells with rounded nuclei. The lumen is absent or very small in the center of the acinus. Serous acini are very few in number (Figure 2).

In young goat of 6 months age the lobes of salivary gland were larger and were clearly divided into lobules by inter lobular connective tissue septa composed of collagen bundle. Most of the glandular tissue composed of mucous and mixed acini. The mucous acinus had narrow lumen. The pyramidal cells had flattened nucleus pressed against the basement membrane. The cell contained zymogenic granules, and lumen occasionally contained mucin. Myoepithelial cells were present at the basement membrane. These findings indicate the active mucous secretory state of the cells. The mucous part of the mixed acini also have flattened nuclei. The serous acini were similar to that of day old kid but number increased (Figure 3).

In adult goat of 2 years the lobes and lobules become largest the serous alveoli are less in number than mucous acini. The mucous acini are similar with that of young goat. The serous acini are similar to that of young goat but the number increases still less than mucous or mixed acini. In mixed alveoli are similar to young goat where pyramidal serous cells with rounded nuclei were capped at the outer margin of mucous acini called serous demilune (Figure 4).

The duct system of this gland is composed of intercalated, interlobular and excretory ducts. All the ducts have regular wider lumen thus easily differentiate from the secretory acini. The intercalated ducts are lined by simple cuboidal or flattened epithelium. The striated ducts are lined by simple columnar epithelia. The large excretory ducts are lined by stratified cuboidal epithelium. Most of the interlobular ducts are surrounded by a layer of connective tissue (Figure 4).

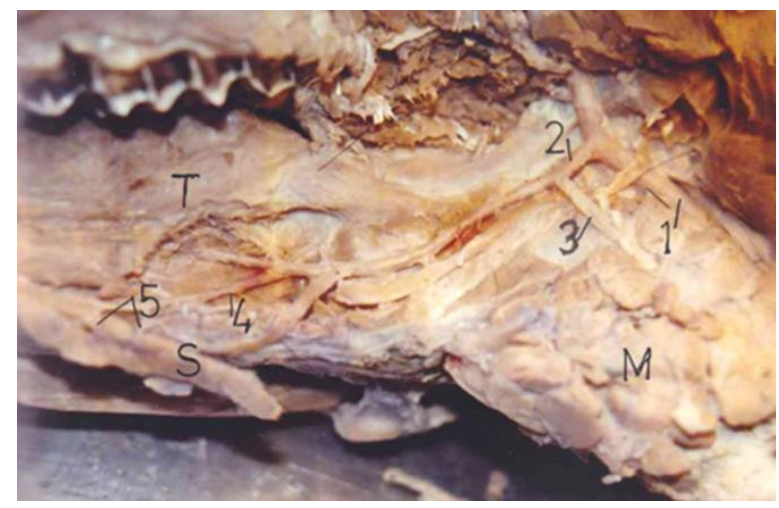

Figure 1. Sub lingual salivary gland of adult goat. $S=$ sublingual salivary gland, $1=$ common carotid artery, 2 = lingual artery, $3=$ mandibular branch of lingual artery, $4=$ sublingual artery, $5=$ twigs originated from sublingual artery which supply to the sublingual salivary gland. 


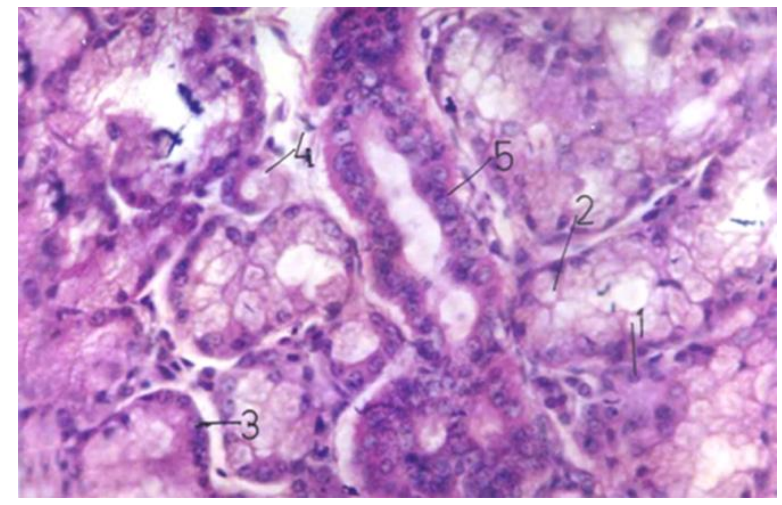

Figure 2. Histology of the sublingual salivary gland of day old goat. $1=$ serous alveoli, $2=$ mucous alveoli, $3=$ mixed alveoli with serous demilune, 4 = intercalated duct, 5 = interlobar duct.

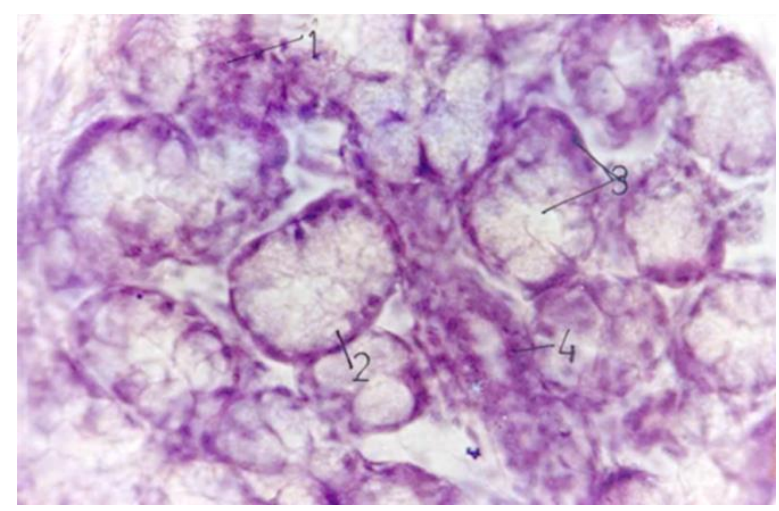

Figure 3. Histology of the sublingual salivary gland of 6 months old goat. $1=$ serous acinus, $2=$ mucous acinus, $3=$ mixed acinus with serous demilune, $4=$ intercalated duct.

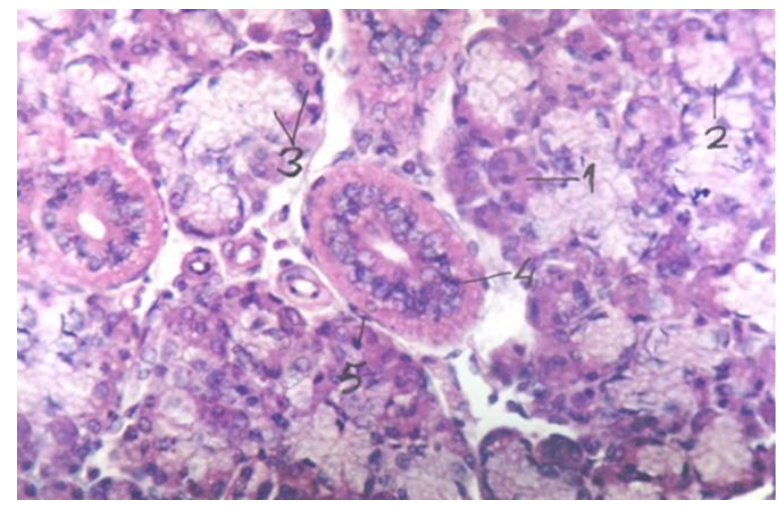

Figure 4. Histology of the sublingual salivary gland of adult goat. $1=$ serous acinus, $2=$ mucous alveoli, 3 $=$ mixed acinus with serous demilune, $4=$ interlobular duct, $5=$ connective tissue.

\section{Discussion}

The sublingual gland is situated between the lower part of the tongue and mylohyoid muscle. It is extended from a little behind the mandibular symphysis to the second or third lower molar tooth. The lateral surface is related to the mylohyoid muscle and the sublingulal nerve, the medial surface is related to the genioglossus muscle, styloglossus muscle and the mandibular duct. These findings are similar to that of Islam (Islam, 1981). In present study the average weight of the sublingual gland in adult goat was $0.8 \mathrm{~g}$. Previous study showed the weight $2.0 \mathrm{~g}$ in adult goat (Islam, 1981). This difference may be due to pure breed goat of this study and cross breed nature of the previous one. The length, breadth and thickness at different age group have not been reported yet in the available literature, what I write in result section. The findings on duct system and blood supply are somewhat similar to the previous studied (Islam, 1981; Hossain, 1975; Habel, 1975). In day old kid 
the lobes are smaller in size and the lobules are indistinct. Interlober septum contains large number of collagen bundle. The glandular units composed of tubuloalveolar acini which are mostly mucous in type. The mucous acini composed of pyramidal cells with rounded nuclei resting on a basement membrane. The acini had distinct lumen. The cells contained rounded nuclei and lacked zymogenic granules indicating less functional state of the glands (Figure 2). Although no available literature regarding the development of sublingual gland in goat for comparison, the development of sublingual gland has been investigated previously in rats. In contrast to the submandibular and parotid glands, sublingual cytodifferentiation is thought to be completed during prenatal development. The rat sublingual rudiment is initiated at day 14 in utero, in the same mesenchymal capsule as the submandibular gland (Redman and Sreebny, 1970). These secretory granule types are: 1) dense (apparently serous), 2) empty-looking (apparently mucous), or 3) "mixed" (mucous-appearing granules with dense cores) (Redman and Ball, 1978). In sublingual gland of day old kid, serous acini were very few in numbers which is supported by the findings in rat. In young goat of 6 months age the lobes of salivary gland became larger and are clearly divided into lobules by interlobular connective tissue septa composed of collagen bundle. Most of the glandular tissue composed of mucous and mixed acinus. The mucous acinus have narrow lumen. The pyramidal cells have flattened nuclei pressed against the basement membrane. The cell contained zymogenic granules, and lumen occasionally contained mucin. Myoepithelial cells are present at the basement membrane. These findings indicate the active mucous secretory state of the cells. This finding has similarities with previous studies on adult goat (Islam, 1982; Trautman and Fiebiger, 1952). In adult goat of 2 years the lobes and lobules become the largest, the serous alveoli are increased in number but less than the mucous and mixed acini. The mucous acini are similar with that of young goat. In mixed alveoli, pyramidal serous cells with rounded nuclei are capped at the outer margin of mucus acini called serous demilune. The serous acini are lined by pyramidal cells with rounded nuclei. The lumen is absent or very small in the center of the acinus. Similar observation were reported in previous study on adult goat (Islam, 1982; Trautman and Fiebiger, 1952). The duct system of this gland is composed of intercalated, interlobular and excretory ducts. Similar observation was found in previous study on adult goat (Islam, 1982).

\section{Conclusions}

Salivary gland is an important organ of mammals which secretes clear, tasteless fluid called saliva. Saliva is secreted into the oral cavity via a series of ducts in the ductal system, and plays diverse roles by having digestive, antibacterial, buffering, lubricant, and water-balance functions.

Dysfunction of salivary secretion causes xerostomia or dry mouth and sequentially leads to severe dental caries as well as oral mucosal disorders. Hyposalivation is caused by systemic diseases such as Sjögren's syndrome and by pharmaceutical side effects, salivary stones, and tumors as well as medical treatments including radiotherapy. The study of the salivary gland forms an important link between the anatomy and surgery. The salivary glands and ducts may be affected by inflammation, calculus formation, rupture or neoplasia. Sialoadenitis is commonly associated with salivary mucoceles. The recognition and treatment of these lesions depend on an adequate knowledge of anatomy. There are three pairs of salivary glands in Black Bengal goat namely parotid, mandibular and sublingual salivary glands. Information regarding the sublingual salivary gland is very limited and confined in adult goat only; data regarding the developmental pattern of the gland are not available. Present study was carried out to fill up the gap of information regarding this gland. The topography, shape, color, relation and morphometry of day old kid, young goat of 6 months age and adult goat of 2 years age are discussed. Formation and course of duct system, arterial supply and venous drainage also discussed. Gradual histological development is observed through this study for the first time. This study provides a convenient baseline for the immune histochemical study to detect various secretory proteins (enzymes/antibodies etc) at different stage of development.

\section{Conflict of interest}

None to declare.

\section{References}

Accili D, MG Gabielli and G Menghi, 1994. Variety of sialic acids occurring in the bovine sublingual salivary gland. Histology and Histopathology J., 9: 723.

Burlage FR, RP Coppes, H Meertens, MA Stokman and A Vissink, 2001. Parotid and submandibular/sublingual flow during high dose radiotherapy. Radiother. Oncol., 61: 271-274.

Devi N S and F Jacoby, 1966. The postnatal development of the submaxillary gland of the goldenhamster. J. Anat., 100: 269-285. 
Dvorak M, 1969. The secretory cells of the submaxillary gland in the perinatal period of development in the rat. Zeitschift fur Zellforschung und mikroskopische Anatomie, 99: 346-356.

Featherstone JD, 2000. The science and practice of caries prevention. J. Am. Dent. Assoc., 131: 887-899.

Fox PC, 1998. Acquired salivary dysfunction. Ann. New York Acad. Sci., 842: 132-137.

Genkins GN, 1978. Saliva In The Physiology and Biochemistry of the Mouth" 4th ed., Blackwell Scientific, Oxford, pp. 284-359.

Golbar HM, T Izawa, V Juniantito, C Ichikawac, M Tanaka, M Kuwamura and J Yamate, 2013. Immunohistochemical characterization of macrophages and myofibroblasts in fibrotic liver lesions due to fasciola infection in cattle. J. Vet. Med. Sci., 75: 857-865.

Habel RE, 1975. Sisson and Grossman's the anatomy of the domestic animals. Ed. by Getty R. $5^{\text {th }}$ ed. Vol 1 , WB Saunders Co. Philadelphia, London, pp. 872-874.

Hossain MI, 1975. The arterial supply to the salivary gland of Black Bengal goat. Ind. Vet. J., 52: 699-702.

Islam MN, 1981. Gross anatomy of the salivary gland of Black Bengal goat. Bangladesh Veterinary Journal, 15: $17-21$.

Islam MN, 1982. Histology and Histochemistryof the salivary glands of Black Bengal goat. Bangladesh Veterinary Journal, 16: 11-15.

Jacoby F, 1959. Observations on the postnatal development of the mouse submaxillary gland. J. Anat., 93: 579.

Jacoby F and CR Leeson, 1959. The postnatal development of the rat submaxillary gland. J. Anat., 93: 201-216.

Pospieszng N, M Kuryszko, A Juszyki and M Damski, 2010. Morphology and histology analysis of mandibular and sublingual glands in pig. Bull Vet. Ins. Pulawy, 54: 351-355.

Rauf SMA, MR Islam and MK Anam, 2004. Macroscopic and microscopic study of the mandibular salivary gland in black Bengal goats. Vet. Med. J., 2: 137

Redman RS and LM Sreebny, 1970. The prenatal phase of the morphosis of the rat parotid gland. Anat. Rec., 168: $127-138$.

Redman RS and WD Ball, 1978. Cytodifferentiation of secretory cells in the sublingual gland of the prenatal rat: a histological, histochemical and ultrastructural study. Am. J. Anat., 153: 367-390.

Reece OW, 2004. Dukes physiology of domestic animals .12th. Ed. Comstock publishing associated a division of Cornell university press, Ithaca and London. PP: 405.

Ship JA, 2004. Xerostomia: aetiology, diagnosis, management and clinical implications. In Saliva and Oral Health, 3rd ed., ed. by M. Edgar, C. Dawes and D. O’Mullane, British Dental Association, London, pp. 4155.

Stephen J, S Ettinger and E Feldman, 2010.Text book of veterinary internal medicine .7th Ed . Vica president and publisher Linda Duncan. pp. 1479.

Takagi K, 1925. Untersuchungen uber die Unterkieferdriise der Katze mit besonderer Berucksichtigung des Chondrions. Zeitschrift fur Zellforschung und mikroskopische Anatomie, 2: 254-270.

Trautman A and J Fiebiger, 1952. Fndamentals of the histology of domestic animals. Comstock Publishing Associations, Ithaca, New York, pp. 153-160.

Vissink A, JB Mitchell, BJ Baum, KH Limesand, SB Jensen, PC Fox, LS Elting, JA Langendijk, RP Coppes and ME Reyland, 2010. Clinical management of salivary gland hypofunction and xerostomia in head-andneck cancer patients: successes and barriers. Int. J. Radiat. Oncol. Biol. Phys., 78: 983-991.

Yamashina S and T Barka, 1972. Localization of peroxidase activity in the developing submandibular gland of normal and isoproterenol-treated rats. J. Histochem. Cytochem., 20: 855-872. 